\title{
Effectiveness of camera-based speed deterrence schemes and drivers' support for a hypothetical smartphone-App-based monitoring scheme
}

\author{
MAHDI SHEHAB * \\ Department of Civil Engineering, College of Technological Studies, PAAET, Kuwait
}

\begin{abstract}
As the economic and health tolls resulting from traffic crashes continue to rise worldwide, the need to cut down on behaviours commonly recognized as contributing factors to crashes becomes vital. Speeding has been identified as a major contributing factor to the occurrence of crashes, with crash severity correlating strongly and positively with driving speed. This study represents an endeavour aiming to enhance traffic safety by addressing issues essential to improving the efforts usually undertaken to confront speeding drivers. The effectiveness of the current scheme of deterring speeding drivers in Kuwait relying mainly on automatic speed cameras was assessed through multiple linear regression analysis utilizing data elicited through self-report questionnaires. Moreover, drivers' support for a hypothetical scheme exploiting smartphone-Apps to constantly monitor driving behaviours of repeated traffic violators was measured. Such smartphone-App-based
\end{abstract}

scheme symbolizes one of many possible innovative solutions that might utilize advances in mobile technologies and driver analytics to improve road safety. The findings from this study showed the current scheme to be ineffective based on reported behaviours by surveyed drivers. The study also demonstrated that the majority of surveyed drivers expressed support for the hypothetical scheme employing smartphone-Apps to provide continuous vigilance of driving behaviours for hazardous drivers. Analysis conducted via a proportional odds model demonstrated that support for the hypothetical scheme was less prominent among habitual speeders and frequent violators of speed limits as well as among young and male drivers.

KEYWORDS: Smartphone-App; Driving behaviour; Speeding; Deterrence scheme; Speed cameras; Kuwait

\section{INTRODUCTION}

Driving behaviour is commonly accepted as the main cause of crashes. One aspect of driving behaviour often associated with crashes is speeding. The occurrence and severities of crashes are both believed to increase with driving speeds. Aarts and van Schagen (2006) conducted an extensive review of literature relating crash frequency and severity with vehicles' speeds. They concluded that both the occurrence and severity of crashes are strongly and positively associated with speeding. Tselentis et al. (2019) have identified speeding as one of the most influencing factors leading to crashes. Koushki et al. (2003) found speeding to be the main cause of approximately $92 \%$ of injury or fatal crashes in Kuwait. The power model (Nilsson, 2004) clearly indicates a robust positive relationship between vehicles' speeds and crash severity. Numerous other studies established strong and positive correlations between drivers' speeding behaviour with crash involvement and severity (Alver et al., 2014; Cameron \& Elvik, 2010; Faber et al., 2009; Gaca \& Pogodzinska, 2017; Muslim et al., 2018; West et al., 1993). Several researchers have found strategies of speed management to be associated with reducing crashes and their severities. Islam et al. (2014) contend that reducing traffic speeds through lowering posted speed limits reduces the number and severity of crashes. Muslim et al. (2018) argue that regulating traffic speed significantly enhances road safety by reducing crash risk. Gaca and Pogodzinska (2017) assert that reducing traffic speeds has a significant impact on reducing traffic crashes. Reducing speed limits on urban residential roads was found to have

* mk.shehab@paaet.edu.kw considerable effects on reducing total, property-damage-only, and severe crashes (Islam \& El-Basyouny, 2015) and on fatal, serious-injury, and slight-injury crashes (Pilkington et al., 2018). Similar contentions were made by Ritchey and Nicholson-Crotty (2011). However, for speed management schemes such as lowering speed limits to be effective, they must be accompanied by enforcement strategies which oblige drivers to respect the posted speed limits. Gaca and Pogodzinska (2017) assert that realizing the potential benefits of reducing speed limits requires strict enforcement of the posted speed limit. Such strict enforcement, according to the authors, would lead to more pronounced reduction in fatal crashes as well as aggregate crashes. Budský and Koucký (2008) identified prevention strategies entailing greater compliance with traffic rules as well as sanction systems among the most influencing factors resulting in reductions in the numbers and severities of crashes.Therefore, it is obvious that efforts aimed at reducing traffic crashes and their severities must strive to reduce speeding by obliging drivers to respect speed limit stipulations. Regulating traffic speed by setting appropriate speed limits and enforcing these speed limits is vital to achieving safe speed, which forms a fundamental component of the Safe System paradigm aiming to minimize, or even eliminate, fatalities and serious injuries resulting from crashes (Doecke et al., 2018; ITF, 2016; Jurewicz, 2010; Turner, 2013).

In Kuwait, the efforts to regulate traffic speed and enforce speed limits have predominantly relied on overt fixed and mobile speed cameras. These cameras have been in use in Kuwait since 1995, and now can be seen on all motorways and major roads. Over $88 \%$ of the $2,989,107$ recorded speeding violations in 2017 were issued through speed cameras (Ministry of Interior, 2018). Notwithstanding the relatively large number of speeding violations issued (relative to the 
$1,315,702$ licensed private drivers in 2017), the effectiveness of the scheme relying mainly on speed cameras remains questionable as no substantial reductions in fatality and injury rates have been recorded. As can be seen in Fig. 1, the rate of fatalities per 100 thousand licensed drivers as well as the rate of injuries per 10 thousand licensed drivers have remained relatively constant and did not drop in response to the fluctuation of speeding violations issued per 50 licensed drivers over the period from 2012 - 2017. Effectiveness of the scheme suggests that drivers who have been fined for speeding would be more compliant with speed limits and/or would reveal less intentions of speeding. Efficiency of the existing scheme needs to be explored on this basis. Meanwhile, drivers' acceptance of any alternative scheme needs to be surveyed prior to proposing such scheme for implementation. This highlights the motivation for conducting this research. The first objective of the current study is to investigate the deterrence effect of the current system of relying on speed cameras by scrutinizing the speeding tendencies of drivers in reference to their violation histories. The second objective is to assess drivers' support of an alternative hypothetical scheme entailing more sustained vigilance of repeated violators' driving behaviours. The hypothetical scheme proposes use of a smartphone-App to achieve the sustained monitoring. Employing smartphone-Apps in monitoring roles has been applied recently in Kuwait to enforce quarantines on arriving passengers as part of the efforts to reduce the spread of the COVID-19 pandemic.

\section{LITERATURE REVIEW}

\subsection{Effectiveness of deterrence schemes}

For a deterrence scheme to be effective, it must have high likelihood of detecting unlawful behaviours. Stephens et al. (2017) found that speeding violators were more concerned with apprehension and the ensuing consequences than with safety deterioration resulting from speeding. The authors claimed that drivers were more likely to exceed speed limits if they believed they can evade punishment. Fleiter et al. (2007) reported that speeding violators cited familiarity with speed detection instruments (i.e., location of speed cameras) as a means to avoid detection, thus allowing them to maintain their speeding habits. Elvik and Christensen (2007) concluded that increasing the amount of fine did not have significant effects on compliance with speed limits. The authors argue that compliance is affected more by the likelihood of apprehension than the amount of fine. Hössinger and Berger (2012) contend that while the best strategy to reduce speeding involves combining stricter enforcement with higher fines, stricter enforcement is the more vital component of a strategy to deter notorious speeders. Ritchey and Nicholson-Crotty (2011)

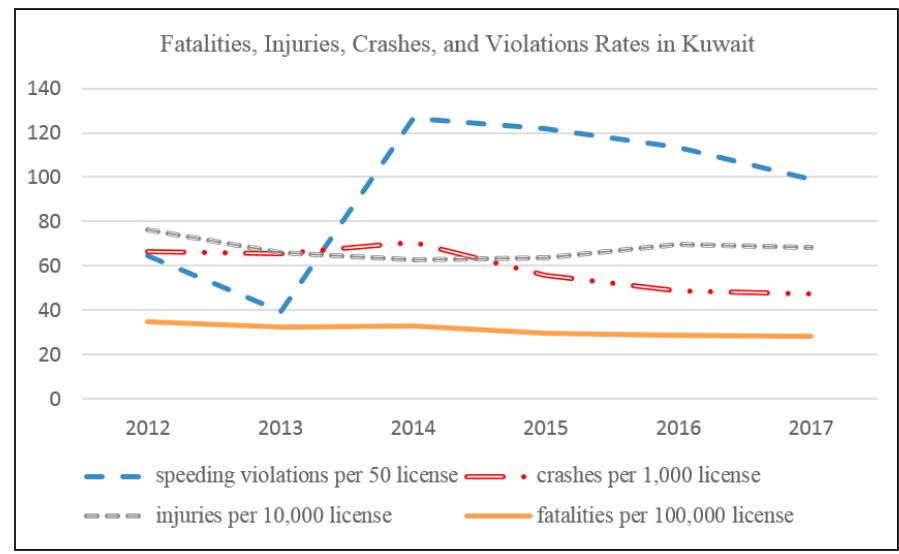

Figure 1: Trends of fatalities, injuries, crashes, and speeding violations in Kuwait argue that the effects of severity of punishment for violating speed limits on reducing fatalities from crashes is negligible when the probability of apprehension for speeding is low. Thus, a conclusion can be reached that for any deterrence scheme to be effective in lowering traffic speeds and hence reducing crashes, such scheme must achieve a high level of certainty of detecting speeding violators. This, in turn, requires persistent monitoring of driving behaviour that is not limited to certain locations or time periods.

\subsection{Common deterrence schemes}

Several deterrence strategies have been deployed to cut down on speeding and other risky driving behaviours. Driver training and education programs and police enforcement of traffic laws are among the earliest efforts attempting to confront this problem. Evidence from previous studies suggests that driver training programs are not effective in reducing crash involvement, and that any positive effects of such programs are short-lived (Mayhew and Simpson, 2002, Peck, 2011). Elliot and Broughton (2005) reported that police enforcement of traffic laws appears to be effective in reducing risky behaviours given that sustained police presence was assured. Similar findings regarding the effectiveness of police presence as a means to deter drivers from speeding have been reported by Ritchey and Nicholson-Crotty (2011) and Yamamura (2008). However, the extensive manpower required for police enforcement to be effective, especially with the ever-expanding fleet of vehicles, renders this strategy impractical.

Another strategy that has been deployed to regulate driving speeds since the late 1980's is fixed and mobile automatic speed cameras that capture spot speeds of passing vehicles. Several empirical and review studies investigated the effectiveness of these speed cameras (De Pauw et al., 2014; Elliot \& Broughton, 2005; Hirst et al., 2005; Liu et al., 2011; Marciano et al., 2015; Thomas et al., 2008). The general conclusions from these studies are that these cameras are effective in reducing speeds and crashes mainly at the locations where they are installed in addition to segments in the immediate vicinity of camera locations. Speeding drivers were found to adapt to the presence of cameras by reducing their speeds prior to the camera location and increasing it after passing it. Moreover, a noticeable diversion of traffic to less monitored roads has been observed, with crashes possibly migrating to alternative roads or to unmonitored sections of the same road. Thus, although speed cameras have been associated with some reduction in average speeds and crashes at specific locations, the overall effect of speed cameras in reducing speeds and crashes on the road network was found to be very limited. Point-to-point speed enforcement system (speed-over-distance cameras) was found to be effective in reducing various measures of speed over extended segments. However, substantial differences in the effectiveness of the system between different roads were observed in addition to significant reductions in effectiveness 2 years after implementing the system (Montella et al., 2015). Another deficiency of this system is the necessity of restricting egress between camera locations to ensure vehicles' passage along both cameras. A more recent deterrence strategy to reduce speeding involves deploying an Intelligent Speed Adaptation (ISA) system which could be used in different roles. The ISA system may be utilized in a warning capacity, alerting the driver when a set speed is exceeded. It may also be deployed in a control capacity, intervening to reduce driving speed through an active accelerator pedal when a certain preset speed is exceeded. Such ISA system was found to successfully reduce speeds for frequent speeders (Vlassenroot et al., 2007).

\subsection{Opportunities from new technologies}

From the brief review of existing deterrence policies, it appears that new and more effective methods of monitoring 
driving behaviours are called for. The advent of mobile technology along with advances in the field of driver analytics have created opportunities for innovative methods of improving driving behaviour to be implemented. One such method exploiting mobile technologies and driver analytics is the use of smartphone-Apps as tools to monitor driving behaviour. Several researchers have utilized smartphoneApps as means of observing driving behaviour. Paefgen et al. (2012) observed that measurements of specific aspects of driving behaviour obtained from a smartphone-App correlated significantly with those obtained from on-board measuring devices. Fazeen et al. (2012) detected unsafe acceleration and lane changing maneuvers through a smartphone-App utilizing internal accelerometer and GPS embedded in the smartphone. However, accuracy of measurements in both studies was affected by the smartphone position, orientation, and/or smartphone use during experiments. Many later studies overcame some of these drawbacks. Hong et al. (2014) reported that a smartphone-App platform was capable of capturing the general movement of vehicles as related to location, speed, linear acceleration, 3D acceleration, and $\mathrm{G}$-force. The platform showed ability to detect aggressive driving with high accuracy. Li et al. (2016) detected risky driving behaviours related to speeding, steering, weaving, and mobile-use distraction utilizing a smartphone-App with high accuracy, regardless of smartphone position or orientation. Vlahogianni and Barmpounakis (2017) measured vehicles' acceleration, braking, and cornering using a smartphone-App. While the smartphone position and orientation did not affect measurements, the accuracy of measurements dropped when subjects conducted the experiments unobserved, possibly due to smartphone use by drivers. Systems deploying smartphone-Apps have proved capable of collecting driving behaviour data continuously for prolonged periods. Musicant and Lotan (2016) conducted a study that utilized a smartphone-App capable of collecting data on speeding, acceleration, braking, and cornering events that impose undesirable G-forces on vehicles and their occupants. Data was collected for periods up to 4 months. Tselentis et al. (2019) successfully assessed safety efficiency of 56 drivers utilizing data about their driving behaviours related to speeding, mobile phone use, acceleration, and braking collected from a smartphone-App for 7 months continuously. Jiang et al. (2017) and Jiang et al. (2020) investigated the effects of a smartphone-App on driving behaviour, where the smartphone-App monitored speeding and acceleration behaviours of drivers among other aspects of driving for 3 months. The results showed that several driver groups significantly improved their driving behaviour through the smartphone-App. These studies show the capability of smartphone-Apps to be deployed in a driver-monitoring capacity, which may form part of an enforcement scheme. Whether drivers accept intervention from such a tool needs to be investigated. Stephens et al. (2017) explored drivers' acceptance of an Intelligent Speed Assist (ISA) system which could improve drivers' compliance with speed limits. They found voluntary acceptance of such system to be low even though the majority of surveyed drivers believed the system could be useful. The authors argue that for the ISA system to be effective, its use must be mandatory, especially for habitual speeders. In an earlier study, Vlassenroot et al. (2007) reported indications of acceptance for a similar Intelligent Speed Adaptation (ISA) system that aims at improving drivers' speeding behaviours through alerting drivers or intervening to reduce speeds.

\subsection{Summary of literature review}

From the review, it is apparent that the predominant method of speeding deterrence in Kuwait, i.e., automatic speeding cameras, has not been assessed adequately from the perspective of individual drivers. The available literature on assessing the effectiveness of this scheme shows reductions in speeds and crashes only in the vicinity of these cameras without addressing their influence on individuals' driving behaviours. Additionally, while new technologies present valuable opportunities for innovative methods of deterring speeding drivers to be implemented, it is essential that the public's acceptance of such new methods is surveyed prior to embarking on the implementation of these new methods. This study endeavours to address these two issues.

\section{METHODS}

\subsection{Approach}

The motivation for conducting this study and the approach employed can be summarized in the flow chart shown in Fig. 2. The desired outcome from road safety programs is to reduce the number of traffic crashes. Safe drivers who comply with traffic laws contribute to this desired outcome as their likelihoods of crash-involvement are low. The focus of programs aiming to improve road safety centres around violators of traffic laws, and more specifically in this case around regular speeders. Frequent speeding violators necessitate implementing deterrence schemes which can alter their driving behaviours. The deterrence scheme currently deployed to achieve this needs to be assessed. If the assessment reveals effectiveness of the scheme, then the desired goal of the scheme is realized and safety on the road network is enhanced. However, if the assessment reveals that the current scheme is ineffective, then another approach to deterring violating drivers needs to be explored.

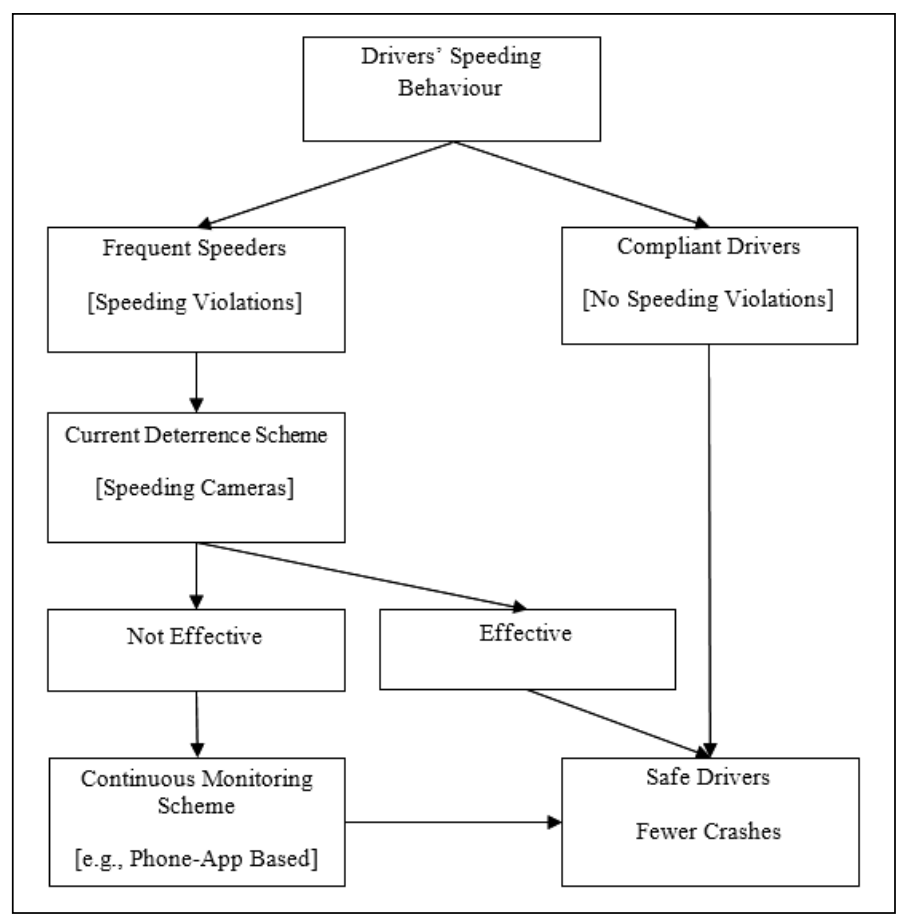

Figure 2: Flow chart of the study approach

The effectiveness of the current deterrence scheme using speed cameras is examined by investigating the relationship between violations history and speeding behaviour. If the current scheme is effective, drivers fined for speeding violations would be expected to report less speeding tendencies. A speed measure representing speeding behaviour is created from items in the questionnaires addressing drivers' tendencies to exceed speed limits and their preferred driving speeds as will be presented in subsection 3.3. This measure is regressed on speeding violations through multiple linear 
regression analysis to determine the nature of the relationship between previous speeding violations and speeding behaviour. Effectiveness of the existing scheme implies that the speed measure should decrease with increases in speeding violations. This can be investigated by examining the value and the sign of the linear coefficient of speeding violations from the linear regression model. The second objective of the study is addressed by examining the level of support for the hypothetical smartphone-App-based scheme from participants' responses. Furthermore, the variation of support for the smartphone-App scheme according to some driver characteristics as well as previous violation history and speeding behaviours is also explored. As the dependent variable for this part of the analyses is on an ordinal scale, the effects of the various factors on the level of support for the hypothetical smartphone-App-based scheme are investigated through an ordinal logistic regression model (proportional odds model). All statistical analyses were conducted at the $95 \%$ confidence level and were performed using the IBM SPSS v.27 software.

\subsection{Data collection}

Data required to fulfill the objectives of the study were elicited through self-report questionnaires. This method has been widely used to measure driving behaviour. Several studies reported strong correlations between self-reported and observed driving speeds (Corbett, 2001, Haglund and Aberg, 2000; Stephens et al., 2017). West et al. (1993) contend that self-reported driving speed is a genuine measure of speeding trends among drivers. The questionnaires prepared for this study sought to obtain a wide range of information about drivers encompassing basic demographic traits, some behavioural tendencies, previous violations and crashes, and their support for a hypothetical scheme utilizing smartphoneApps. Arabic versions of the questionnaires were created by Microsoft Forms and were made available online. Participation in the survey was pursued through various social media platforms and smartphone-Apps such as WhatsApp, Twitter, and Instagram. This method of dissemination allows participants to respond at their convenience in private settings, which could reduce the possible effects of social desirability often cited as sources of bias in self-report studies (Lajunen \& Summala, 2003; Sullman \& Taylor, 2010). Links to the questionnaires were broadcasted through the various platforms in May, 2020. A caveat preceding the actual questionnaire made it clear for participants that full anonymity of participants was assured. No personal information such as participant's name or phone number were required in the questionnaires. Furthermore, a statement in the caveat clearly stressed that the information provided would be used for research purposes only.

\subsection{The Questionnaire}

Driver's age, gender, and annual driving distance were acquired as the main drivers' characteristics investigated in this study. Other characteristics acquired but not used in this study include driver's nationality, vehicle type, and vehicle's year of manufacture. Age was divided into six categories starting with the legal age of licensure in Kuwait as follows: $18-25,26-35,36-45,46-55,56-65$, and over-65 years of age. For annual driving distance, 5 classes were included: $1-10,000 \mathrm{~km}, 10,001-20,000 \mathrm{~km}, 20,001-30,000 \mathrm{~km}$, $30,001-40,000 \mathrm{~km}$, and over-40,000 km annually. In order to distinguish non-active drivers and remove them from the analyses, a further category was included of "not driving a vehicle currently". Participants were also polled on their level of support for implementing a smartphone-App-based scheme that monitors the driving behaviour of repeated traffic offenders. The notion of deploying smartphone-Apps in a law-enforcement role was familiar to the general public during the time of dissemination of the surveys due to the use of similar smartphone-Apps to enforce quarantines as part of the country's efforts to combat the COVID-19 pandemic. Participants were informed that such scheme, if applied, would compel repeated traffic offenders to undergo constant monitoring while driving via a smartphone-App installed on their smartphones to constantly monitor their driving behaviour. A similar survey measuring drivers' acceptance of a deterrence scheme has been carried out by Stephens et al. (2017). In the current survey, participants were asked: do you support obliging repeated violators of traffic laws to undergo a sustained monitoring scheme via a smartphone-App to constantly monitor their driving behaviour? The responses were on a 5-point Likert scale of strongly support, support, neutral, oppose, and strongly oppose.

The behavioural aspects addressed in the questionnaires were drivers' seatbelt use, compliance with speed limits, and preferred speeds. Regarding seatbelt use, participants were asked how often they used seatbelts while driving? The responses were on a 5-point Likert scale: "always", "mostly", "sometimes", "rarely", and "never". For speed limit compliance, participants were asked how often they exceeded the speed limit on motorways when traffic levels did not impede free flow and when road and weather conditions permitted them to drive at their desired speeds in the absence of any speed limit enforcement tools. The responses were also on a 5-point Likert scale: "always", "mostly", "sometimes", "rarely", and "never". The emphasis on motorway driving in this item was based on remarks reported by De Pauw et al. (2014) that most speeding violations occur on motorways. Another behavioural aspect acquired was drivers' preferred speeds on motorways. Participants were asked to reveal their preferred driving speeds on highways and motorways under favorable weather and road surface conditions, with sufficient lighting provided, under light traffic conditions, and while driving on sections with no speed monitoring instruments. The possible responses were under $60 \mathrm{~km} / \mathrm{h}$, $60-80 \mathrm{~km} / \mathrm{h}, 80-100 \mathrm{~km} / \mathrm{h}, 100-120 \mathrm{~km} / \mathrm{h}, 120-140 \mathrm{~km} / \mathrm{h}$, and over $140 \mathrm{~km} / \mathrm{h}$. Besides the behavioural aspects, speeding violations were also attained from the questionnaires, where participants were asked how many speeding violations they have received in the previous 3 years? Participants reported the number of speeding violations selecting from 1-10 or selecting a further category if they received more than 10 violations. Crash involvement in the previous three years was also sought in the questionnaires but not used in the current study as the objective of the study was to determine the effectiveness of the current deterrence scheme based on fines for speeding violations.

\section{RESULTS}

Responses were received online from 1120 participants. After removing questionnaires completed by non-active drivers and those not completed fully, the analyses were carried out on 1079 participants distributed according to the various characteristics as shown in Table 1 . Due to their small sample size, drivers aged over 65 were combined with the 56-65 drivers. This group is referred to hereafter as the over-55 group. In the analyses, annual driving distance was reduced to 3 categories as was done in Martinussen et al. (2013). This was done to overcome some imbalances in sample sizes and to reduce the number of cells in the models. The categories were selected to reflect the overwhelming reliance on personal vehicular travel as the dominant mode of transport in Kuwait. The reduced categories of annual driving distance were $1-10,000 \mathrm{~km}, 10,001-30,000 \mathrm{~km}$, and over $30,000 \mathrm{~km}$ corresponding to low, moderate, and high annual distance 
drivers, respectively. Also shown in Table 1 are the responses regarding drivers' seatbelt use and speeding related items in the questionnaires. The rate of seatbelt use inferred from "always" seatbelt users was $52.6 \%$, while the speed limit compliance rate derived from participants "never" exceeding speed limits was $32.9 \%$.

In the study sample, female drivers were under-represented, as their percentage in the sample was $33.7 \%$ compared with their percentage in the driving population of approximately $39.4 \%$, according to the most recent available statistics (Ministry of Interior, 2018). Comparison of age distribution in the sample with that in the population estimated from 2019 census (Central Statistical Bureau, 2019) revealed that drivers aged 18-25 were under-represented by approximately $4.8 \%$, while drivers aged $26-55$ and those over55 were over-represented by approximately $2.3 \%$ and $2.5 \%$, respectively. The average speeding violation per driver in the sample was approximately 2.1 violations per driver compared to 2.27 in the driver population (Ministry of Interior, 2018). These comparisons demonstrate that while the sample did not perfectly correspond with the driver population, the discrepancies were mild and may not be considered significant source of bias.

\subsection{Effectiveness of existing deterrence scheme}

To investigate the effectiveness of the current scheme relying mainly on speed cameras, a speeding measure was created from two items in the questionnaire, frequency of exceeding the speed limit and preferred speed. The responses to exceeding the speed limit item were quantified by assigning numerical scores from 1 to 5 , where 1 reflects never exceeding the speed limit and 5 indicates always exceeding the speed limit when conditions permit. Similarly, responses to the preferred speed on motorways were designated with numerical scores from 1-6, where those preferring to drive at speeds less than $60 \mathrm{~km} / \mathrm{h}$ were assigned a score of 1 while those preferring to drive at speeds in excess of $140 \mathrm{~km} / \mathrm{h}$ were assigned a score of 6 . The speeding measure was the sum of the two scores, with a higher score indicating greater tendency to speed. The highest possible score was 11 and the lowest was 2 . The average score of the speed measure was 6.276 and the standard deviation was 1.604 . The kurtosis of this measure was -0.305 and the skewness was 0.391 , indicating very mild departures from the normal distribution. A simple linear regression model was initially fitted with the speed measure as the dependent variable and the number of speeding violations in the previous 3 years as the independent variable to explore the direction of correlation between the two variables. The linear coefficient for speeding violations was 0.234 , signifying a positive correlation between speeding violations and speeding behaviour. In order to investigate the effects of speeding violations on the speed measure while accounting for other factors, a multiple linear regression model was fitted with speeding violations, driver's age, gender, annual driving distance, and seatbelt use as independent variables. Indicator variables were used to represent age, gender, seatbelt use, and annual driving distance in the multiple linear regression model as these were categorical variables. For this analysis, age was divided into three categories to limit the number of indicator variables used in the model. Drivers aged 18-35 were considered the young group, drivers aged 36-55 formed the middle-age group, while those aged over-55 were labeled the old group. These age categories were selected based on results from Rajalin (1994). Seatbelt use was divided into 3 categories: "always", "mostly-or-sometimes", and "rarely-or-never" as done in Hunter et al. (1993). The results from the multiple linear regression model showed that speeding violations, age, and gender had significant effects on the speed measure. Annual driving distance did not have significant effects on the speed measure and was removed from the model. Seatbelt use was statistically significant for the "rare-ornever" group only, and hence was retained in the model. The $\mathrm{R}$-square value for the final model was 0.233 . Although this value indicates that only $23.3 \%$ of the variation in the speed measure could be accounted for by the model, such low explanatory power is not unexpected in studies utilizing Likert-type responses to gauge driving behaviour (Aguinis et al., 2009) or in studies with relatively large sample sizes (Reisinger, 1997). The ANOVA F-test indicated aptness of the model ( $\mathrm{p}$-value $<0.001)$. The maximum Cook's distance for the model was 0.015 , dismissing any possible outlier effects. Factor significances, regression coefficients, standard-

\begin{tabular}{|c|c|c|c|c|c|c|}
\hline \multirow{2}{*}{$\begin{array}{l}\text { Characteristic } \\
\text { Age }\end{array}$} & \multicolumn{6}{|c|}{ Category } \\
\hline & $18-25$ & $26-35$ & $36-45$ & $46-55$ & $56-65$ & Over 65 \\
\hline & 138 & 190 & 232 & 312 & 183 & 24 \\
\hline & $12.8 \%$ & $17.6 \%$ & $21.5 \%$ & $28.9 \%$ & $17.0 \%$ & $2.2 \%$ \\
\hline \multirow[t]{3}{*}{ Gender } & Female & Male & & & & \\
\hline & 364 & 715 & & & & \\
\hline & $33.7 \%$ & $66.3 \%$ & & & & \\
\hline \multirow[t]{3}{*}{ Annual Distance } & $1-10,000$ & $10,001-20,000$ & $20,001-30,000$ & $30,001-40,000$ & Over 40,000 & \\
\hline & 221 & 343 & 283 & 140 & 92 & \\
\hline & $20.5 \%$ & $31.8 \%$ & $26.2 \%$ & $13.0 \%$ & $8.5 \%$ & \\
\hline \multirow[t]{3}{*}{ Seatbelt Use } & Always & Mostly & sometimes & rarely & Never & \\
\hline & 568 & 181 & 147 & 111 & 72 & \\
\hline & $52.6 \%$ & $16.8 \%$ & $13.6 \%$ & $10.3 \%$ & $6.7 \%$ & \\
\hline \multirow[t]{3}{*}{ Exceed Speed Limit } & Always & Mostly & Sometimes & Rarely & Never & \\
\hline & 30 & 124 & 275 & 295 & 355 & \\
\hline & $2.8 \%$ & $11.5 \%$ & $25.5 \%$ & $27.3 \%$ & $32.9 \%$ & \\
\hline \multirow[t]{3}{*}{ Preferred Speed $(\mathrm{Km} / \mathrm{h})$} & $<60$ & $60-80$ & $80-100$ & $100-120$ & $120-140$ & $>140$ \\
\hline & 6 & 28 & 211 & 534 & 271 & 29 \\
\hline & $0.6 \%$ & $2.6 \%$ & $19.5 \%$ & $49.5 \%$ & $25.1 \%$ & $2.7 \%$ \\
\hline
\end{tabular}

Table 1. Distribution of participants according to survey items 


\begin{tabular}{|c|c|c|c|c|c|c|}
\hline Variable & Category & P-Value & Model Coefficient & Standardized Coefficient & Semi-partial Correlation & VIF \\
\hline Speeding Violations & & 0.000 & 0.179 & 0.304 & 0.285 & 1.133 \\
\hline \multirow[t]{2}{*}{ Age } & Young & 0.000 & 0.882 & 0.251 & 0.181 & 1.929 \\
\hline & Middle Aged & 0.041 & 0.241 & 0.075 & 0.055 & 1.850 \\
\hline Gender & & 0.000 & 0.589 & 0.172 & 0.163 & 1.112 \\
\hline Seatbelt & Mostly/Sometimes & 0.862 & 0.018 & 0.005 & 0.005 & 1.186 \\
\hline Use & Rarely/Never & 0.026 & 0.280 & 0.065 & 0.060 & 1.177 \\
\hline
\end{tabular}

Table 2. Parameters from the multiple linear regression model

\begin{tabular}{|c|c|c|c|c|c|}
\hline Variable & Significance Level & Reference Category & Investigated Category & Parameter & Odds Ratio \\
\hline \multirow[t]{4}{*}{ Age } & $<0.001$ & Over-55 & $18-25$ & $-0.890^{*}$ & 0.411 \\
\hline & & & $26-35$ & $-0.477^{*}$ & 0.621 \\
\hline & & & $36-45$ & $-0.044^{* * *}$ & 0.957 \\
\hline & & & $46-55$ & $0.182^{\ldots *}$ & 1.200 \\
\hline Gender & 0.048 & Male & Female & $0.255^{* *}$ & 1.291 \\
\hline Speeding Violations & $<0.001$ & - & - & $-0.092^{*}$ & 0.912 \\
\hline Speed Measure & $<0.001$ & - & - & $-0.172^{*}$ & 0.842 \\
\hline
\end{tabular}

Table 3. Parameters from the proportional odds model

ized coefficients, semi-partial correlations, and VIF values are shown in Table 2.

The low VIF values show that multicollinearity did not affect the model. The model coefficient for speeding violations was 0.179 and the standardized coefficient was 0.304 , confirming the significant and positive association between the speed measure and speeding violations. This result indicates that drivers who reported more speeding violations in the previous three years were more likely to report exceeding speed limits and/or prefer driving at high speeds, thus suggesting the ineffectiveness of the current deterrence scheme. The model further showed that young drivers and male drivers were also more likely to drive at higher speeds and/or exceed speed limits, as were drivers who reported using seatbelts "rarely-or-never".

\subsection{Support for the hypothetical smartphone-App scheme}

Responses to the question concerning drivers' support for a hypothetical smartphone-App-based scheme clearly showed strong support for the scheme. Of the 1079 questionnaires analyzed, 493 participants (45.7\%) reported to "strongly support" the scheme while 319 participants (29.6\%) indicated "support" for the scheme. In contrast, 68 participants (6.3\%) replied with "oppose" and another 40 participants (3.7\%) reported to "strongly oppose" the scheme. The remaining 159 participants (14.7\%) reported being "neutral" in this regard. In order to investigate the variation of support for the scheme across the different driver groups, responses were quantified with numeric scores from 1-5, with a response of "strongly support" receiving a score of 5 and the other end of the response spectrum "strongly oppose" receiving a score of 1.

Participants' responses to this item were analyzed through a proportional odds model, where the dependent variable was the responses to this item in the questionnaires. Two types of independent variables were included, categorical and continuous. Age, gender, annual driving distance, and seatbelt use were entered as categorical variables. The continuous variables consisted of the number of speeding violations and the speed measure constructed from frequency of exceeding speed limits and preferred speeds. Variables were inserted in the model stepwise starting with the continuous variables and then adding the categorical variables individu- ally. Neither annual driving distance nor seatbelt use had any significant effects on the dependent variable. The final model had age and gender as categorical independent variables and the speed measure and the number of speeding violations as continuous independent variables. The likelihood ratio Chi-square test for the model yielded a p-value $<0.001$, while the Pearson and Deviance goodness-of-fit tests returned p-values of 0.103 and 1.000, respectively. These results suggest that the model was appropriate to analyze the data. The test of parallel lines returned a p-value of 0.105 , indicating that the ordinal responses were equally distanced and hence the assumption of proportional odds was confirmed, further supporting the suitability of the model. The Nagelkerke pseudo-R-square value for the model was 0.126. Unlike $\mathrm{R}$-square in ordinary least square regression, this parameter does not represent the amount of variation accounted for by the model, but rather may indicate the level of improvement of the model compared to the intercept-only model (Hemmert et al., 2016). The obtained value of 0.126 may provide further support for the suitability of the model when taking into account the sample size of the current study, based on the recommended benchmark values for pseudo-R-square of binary logistic regression models in Hemmert et al. (2016). The $\mathrm{p}$-values, parameter estimates, and odds ratios for the different independent variables are shown in Table 3.

Female drivers were over $29 \%$ more likely than male drivers to support this scheme. Drivers from the 18-25 and 26-35 age groups were significantly less likely than over- 55 drivers to support the scheme $(58.9 \%$ and $37.9 \%$ less likely, respectively). Drivers from the other two age groups (36-45 and 46-55) did not differ significantly from the over-55 drivers in supporting the hypothetical scheme. The number of previous speeding violations was significantly and negatively correlated with supporting the scheme, with an odds ratio of 0.912. This implies that with every increase of one speeding violation during the previous 3 years, drivers were approximately $9 \%$ less likely to support this scheme. As for speeding behaviour, the speed measure was also significantly and negatively associated with supporting the scheme, with an odds ratio of 0.842 . This indicates that with every increase of one point in their speed measure, drivers were approximately $16 \%$ less likely to support the scheme. 


\section{DISCUSSION}

Investigation of the current speed deterrence scheme proved that it is ineffective. Drivers with previous speeding fines were not found to abandon their speeding habits. To the contrary, they were found to be more likely to exceed speed limits and/or to favor driving at higher speeds. A possible explanation for this finding is that speeding drivers are not deterred by the presence of speeding cameras as they have learned to evade detection by these cameras. They reduce their speeds only at the locations where their speeds are monitored, i.e., camera locations. The current scheme lends itself to such adjustments by violating drivers, since the existing vigilance mechanism is limited to those locations where speeding cameras are positioned. This may not only fail to deter speeding drivers from driving at high speeds, but may also cause additional dangers by the abrupt and often unexpected changes of speeds executed by speeding drivers near camera locations. Regarding driver traits, young drivers, male drivers, and less frequent users of seatbelts were also found to be more likely to exceed speed limits and/or to prefer driving at high speeds. On the other hand, drivers' inclinations to exceed speed limits and/or to prefer driving at higher speeds were not affected by their annual driving distances.

A more effective strategy to force violating drivers to respect traffic rules would be compelling these drivers to have their driving behaviours monitored constantly. Elvik and Christensen (2007) state that "the regulation of speed is a continuous component of the driving task in which violations may occur at almost any time and compliance requires continuous monitoring". The advances achieved in mobile technology present a unique opportunity to implement such constant vigilance at very low costs. This study surveyed drivers on their acceptance of a hypothetical scheme that entails obliging repeated violators of traffic rules to undergo continuous monitoring of their driving behaviour via a smartphoneApp. The results demonstrated sound support for the scheme, with more than $75 \%$ of the surveyed drivers supporting it. Support for the scheme was expectedly lower among young drivers and male drivers, shown in this study and in the literature to be more likely to violate speeding regulations. Support for this scheme was also noticeably lower among drivers with previous speeding violations and even more among frequent speeders. Interestingly, the percentage of drivers expressing opposition for the scheme was only $10 \%$. This indicates that while safe drivers were understandably in support of this scheme, many of the habitual speeders were also in support of the scheme as it would oblige them to adopt safer driving behaviours. In the absence of a mechanism that forces unsafe drivers to alter their speeding habits, they might find it difficult to change their behaviour even if they accepted that it is unsafe.

For the proposed smartphone-App scheme to be effective, some issues related to the functionality of the smartphoneApp raised in the literature must be addressed. Hong et al. (2014) noted that smartphone-Apps rely on GPS data to produce measures of driving behaviours. Thus, these measures may not be accurate near large buildings or in tunnels. Any smartphone-App prepared for purposes of monitoring driving behaviour must address this shortcoming. Moreover, Vlahogianni and Barmpounakis (2017) remarked that any smartphone-App prepared for observing driving behaviour must also distinguish between occasions when the smartphone owner is the vehicle's driver or a passenger. Another issue that needs to be addressed is the liability of drivers undergoing the monitoring scheme to maintain the App active while driving. Laying out the specific details pertaining to functionality of the smartphone-App to enable it to form a vital component of a comprehensive deterrence scheme requires cooperation and coordination between legislators, transportation specialists, technical experts, and concerned authorities.

As with most self-report studies, a possible limitation associated with the current study relates to the validity of the collected data and whether such data reflects actual conditions. Such limitation arises from the nature of the data collection method which could make the data susceptible to social desirability and recall bias effects. However, several outcomes from the study suggest that social desirability and recall bias concerns were unlikely to have influenced the study findings considerably. The findings obtained here regarding the effects of age, gender, and seatbelt use on speeding behaviours were in strong conformance with results found in the literature. Furthermore, social desirability effects generally manifest as under-stating unacceptable behaviours rather than overstating acceptable ones (Lindeman \& Verkasalo, 1994). Since the reported behaviours in this study indicated considerable non-compliance with traffic rules exemplified by the low seatbelt and speed limit compliance rates, the likelihood that the data collection method led to biased or drastically unrealistic results is very low. Additionally, the average number of speeding violations reported in the study sample did not deviate markedly from that of the driver population, thus reducing the concerns about the validity of the self-reported violations obtained in the study. Other limitations associated with this study might be related to confining participation only to Arabic language speakers, which resulted in eliminating non-Arabic speaking drivers from participation, albeit their percentage in the driver population is not substantial.

\section{CONCLUSIONS}

This study assessed the effectiveness of the predominant deterrence scheme of speeding behaviours currently deployed in Kuwait. The study showed ineffectiveness of the vigilance scheme relying mainly on speed cameras to deter speeding drivers. The conclusion reached in this regard is that drivers with previous speeding violations were more likely to uphold their speeding habits. The nature of the current scheme presents an opportunity for repeated violators to sustain their unsafe speeding habits as they become familiar with the locations where their speeds are monitored and alter their behaviours only at these locations. This calls for a more persistent vigilance scheme, where repeated violators' driving behaviours are monitored constantly. One possible avenue to achieve this objective with little financial cost is exploiting the advances in mobile technologies. The successful deployment of smartphone-Apps for quarantine enforcement purposes as part of the nation's efforts to stop the spread of the COVID-19 pandemic opened the door for using similar strategies to enforce drivers' compliance with traffic rules including speeding regulations. Support for a hypothetical scheme involving compelling repeated violators of speeding regulations to undergo constant monitoring through a smartphone-App was investigated. The majority of surveyed drivers were in support of such scheme. Support for this hypothetical scheme was distinctly lower among drivers with more previous speeding violations and also among drivers with excessive self-reported speeding habits. Support for the scheme was also lower among younger drivers and male drivers, found in this study and generally in the literature to be more prone to violating speeding regulations.

Future research to ensue from this study entails conducting similar surveys on larger samples while laying out more details of the hypothetical scheme including the duration and conditions of undergoing the scheme for violators. In addition, carrying out similar studies in different countries with varying social and driving cultures may provide more 
information on acceptance of the smartphone-App-based scheme. More importantly, a prototype smartphone-App needs to be implemented on selected driver groups while monitoring the changes in their driving behaviour during specified time periods to learn more about the effectiveness of this approach. This may also help identify flaws that must be modified before implementing the scheme on a large scale.

\section{REFERENCES}

Aarts, L., \& van Schagen, I. (2006). Driving speed and the risk of road crashes: A review. Accident Analysis and Prevention, 38, 215-224.

Aguinis, H., Pierce, C. A., \& Culpepper, S. A. (2009). Scale coarseness as a methodological artifact correcting correlation coefficients attenuated from using coarse scales. Organizational Research Methods, 12(4), 623-652.

Alver, Y., Demirel, M. C., \& Mutlu, M. M. (2014). Interaction between socio-demographic characteristics: Traffic rule violations and traffic crash history for young drivers. Accident Analysis and Prevention, 72, 95-104. https://doi.org/10.1016/j. aap.2014.06.015.

Budský, R. \& Koucký, M. (2008). Statistical analysis of the impact of selected factors on the rate of accidents. Transactions on Transport Sciences, 1(1), 37-42. DOI: 10.5507/tots.2008.005

Cameron, M. H., \& Elvik, R. (2010). Nilsson's Power Model connecting speed and road trauma: Applicability by road type and alternative models for urban roads. Accident Analysis and Prevention, 42, 1908-1915.

Central Statistical Bureau, State of Kuwait. (2019). Population estimates in Kuwait by age, nationality, and sex, 2019. Retrieved from https://www.csb.gov.kw/Pages/ Statistics?ID=67\&ParentCatID=1. Last accessed July 17 $17^{\text {th }}, 2020$.

Corbett, C. (2001). Explanations for "understating" in self-reported speeding behaviour. Transportation Research Part F, 4, 133-150.

De Pauw, E., Daniels, S., Brijs, T., Hermans, E., \& Wets, G. (2014). Behavioral effects of fixed speed cameras on motorways speed: Overall speed compliance or kangaroo jump. Accident Analysis and Prevention, 73, 132-140. https://doi.org/10.1016/j. aap.2014.08.019

Doecke, S. D., Kloeden, C. N., Dutschke, J. K., \& Baldock, M. R. J. (2018). Safe speed limits for a safe system: The relationship between speed limit and fatal crash rate for different crash types. Traffic Injury Prevention, 19(4), 404-408. https://doi.org/1 0.1080/15389588.2017.1422601

Elliott, M., \& Broughton, J. (2005). How methods and levels of policing affect road casualty rates (TRL, report TRL637. Wokingham, UK). Transport Research Laboratory.

Elvik, R., \& Christensen, P. (2007). The deterrent effect of increasing fixed penalties for traffic offences: The Norwegian experience. Journal of Safety Research, 38, 689-695. https://doi.org/10.1016/j.jsr.2007.09.007

Faber, J., Lisá, Z., \& Novák, M. (2009). Driver behavior influenced by an aggressive factor. Transactions on Transport Sciences, 2(2), 68-73. DOI: $10.5507 /$ tots.2009.011

Fazeen, M., Gozick, B., Dantu, R., Bhukhiya, M., \& Gonzalez, M.C. (2012). Safe driving using mobile phones. IEEE Transactions on Intelligent Transportation Systems, 13, 1462-1468.

Fleiter, J., Lennon, A., \& Watson, B. (2007). Choosing not to speed: A qualitative exploration of differences in perceptions about speed limit compliance and related issues. Proceedings Australian Road Safety Research Policing and Education Conference, Melbourne, Victoria (pp. 1-14).

Gaca, S., \& Pogodzinska, S. (2017). Speed management as a measure to improve road safety on Polish regional roads. Archives of Transport, 43(3), 29-42. DOI: 10.5604/01.3001.0010.4225
Haglund, M., \& Aberg, L. (2000). Speed choice in relation to speed limit and influences from other drivers. Transportation Research Part F, 3, 39-51.

Hemmert, G. A. J., Schons, L. M., Wieseke, J., \& Schimmelpennig, H. (2016). Log-likelihood-based pseudo- $\mathrm{R}^{2}$ in logistic regression: Deriving sample-sensitive benchmarks. Sociological Methods E Research, 47(3), 507-531. DOI:10.1177/0049124116638107

Hirst, W. M., Mountain, L. J., \& Maher, M. J. (2005). Are speed enforcement cameras more effective than other speed management measures? An evaluation of the relationship between speed and accident reductions. Accident Analysis and Prevention, 37, 731-741.

Hong, J. H., Margines, B., \& Dey, A. K. (2014). A smartphone-based sensing platform to model aggressive driving behaviors. Proceedings of the SIGCHI Conference on Human Factors in Computing Systems (pp. 4047-4056). New York, NY: ACM.

Hunter, W. W., Stewart, J. R. Stutts, J. C., \& Rodgman, E. A. (1993). Observed and self-reported seat belt wearing as related to prior traffic accidents and convictions. Accident Analysis and Prevention, 5(5), 545-554.

Hössinger, R., \& Berger, W. J. (2012). Stated response to increased enforcement density and penalty size for speeding and driving unbelted. Accident Analysis and Prevention, 49, 501-511. https://doi.org/10.1016/j.aap.2012.03.023

Islam, M. T., El-Basyouny, K. \& Ibrahim, S. E. (2014). The impact of lowered residential speed limits on vehicular speed behavior. Safety Science, 62, 483-494. https://doi.org/10.1016/j. ssci.2013.10.006

Islam, M. T., \& El-Basyouny, K. (2015). Full Bayesian evaluation of the safety effects of reducing the posted speed limit in urban residential area. Accident Analysis and Prevention, 80, 18-25. https://doi.org/10.1016/j.aap.2015.02.026

ITF (2016). Zero road deaths and serious injuries: Leading a paradigm shift to a safe system. OECD Publishing, Paris. http://dx.doi.org/10.1787/9789282108055-en

Jiang, Y., Zhang, J., Chikaraishi, M., Seya, H., \& Fujiwara, A. (2017). Effects of a GPS-enabled smart phone app with functions of driving safety diagnosis and warning information provision on over-speeding violation behavior on expressways Transportation Research Procedia, 25, 1815-1823. https://doi. org/10.1016/j.trpro.2017.05.154

Jiang, Y., Zhang, J., Wang, Y., \& Wang, W. (2020). Drivers' behavioral responses to driving risk diagnosis and real-time warning information provision on expressways: A smartphone app-based driving experiment. Journal of Transportation Safety and Security, 12(3), 329-357. https://doi.org/10.1080/19439962.2018.1483988

Jurewicz, C. (2010). Speed limits in the safe system context. Journal of the Australasian College of Road Safety, 21(2), 14-17.

Koushki, P. A., Bustan, M. A., \& Kartam, N. (2003). Impact of safety belt use on road accident injury and injury type in Kuwait. Accident Analysis and Prevention, 35, 237-241.

Lajunen, T., \& Summala, H. (2003). Can we trust self-reports of driving? Effects of impression management on driver behaviour questionnaire responses. Transportation Research Part F, 6, 97-107.

Li, F., Zhang, H., Che, H., \& Qiu, X. (2016). Dangerous driving behavior detection using smartphone sensors. Proceedings $19^{\text {th }}$ International Conference on Intelligent Transportation Systems (ITSC), Rio De Janeiro, Brazil (pp. 1902-1907).

Lindeman, M., \& Verkasalo, M. (1994). Personality, situation, and positive-negative asymmetry in socially desirable responding. European Journal of Personality, 9, 125-134.

Liu, P., Zhang, X., Wang, W., \& Xu, C. (2011). Driver response to automated speed enforcement on rural highways. Transportation Research Record, 2265, 109-117. https://doi.org/10.3141/2265-12

Marciano, H., Setter, P., \& Norman, J. (2015). Overt vs covert speed cameras in combination with delayed vs immediate feedback to the offender. Accident Analysis and Prevention, 79, 231-240. https://doi.org/10.1016/i.aap.2015.03.028 
Martinussen, L. M., Hakamies-Blomqvist, L., Møller, M., Lajunen, T., \& Özkan, T. (2013). Age, gender, mileage and the DBQ: The validity of the Driver Behaviour Questionnaire in different driver groups. Accident Analysis \& Prevention, 52, 228-236. https://doi.org/10.1016/j.aap.2012.12.036

Mayhew, D. R., \& Simpson, H. M. (2002). The safety value of driver education and training. Injury Prevention, 8 (Suppl. II), ii3-ii8.

Ministry of Interior, State of Kuwait. (2018) Traffic Statistics 2017. Retrieved from https://www.moi.gov.kw/gdt/Statistics2.htm\#. Last accessed July $28^{\text {th }}, 2020$.

Montella, A., Punzo, V., Chiaradonna, S., Mauriello, F., \& Montanino, M. (2015). Point-to-point speed enforcement systems: Speed limits design criteria and analysis of drivers' compliance. Transportation Research Part C, 53, 1-18. https://doi.org/10.1016/j.trc.2015.01.025

Musicant, O., \& Lotan, T. (2016). Can novice drivers be motivated to use a smartphone based app that monitors their behavior? Transportation Research Part F, 42(3), 544-557.

Muslim, N. H. B., Shafaghat, A., Keyvanfar, A., \& Ismail, M. (2018). Green Driver: Driving behaviors revisited on safety. Archives of Transport, 47(3), 49-78. DOI: 10.5604/01.3001.0012.6507

Nilsson, G. (2004). Traffic safety dimensions and the Power Model to describe the effect of speed on safety. Doctoral thesis. Lund University, Department of Technology and Society, Traffic Engineering.

Paefgen, J., Kehr, F., Zhai, Y., \& Michahelles, F. (2012). Driving behavior analysis with smartphones: Insights from a controlled field study. Proceedings of the $11^{\text {th }}$ International Conference on Mobile and Ubiquitous Multimedia (article 36). New York, NY: ACM.

Peck, R. C. (2011). Do driver training programs reduce crashes and traffic violations? A critical examination of the literature. IATSS Research, 34, 63-71.

Pilkington, P., Bornioli, A., Bray, I., \& Bird, E. (2018). The Bristol twenty miles per hour limit evaluation (BRITE) study. Project Report. University of the West of England. Retrieved from http://eprints.uwe.ac.uk/34851

Rajalin, S. (1994). The connection between risky driving and involvement in fatal accidents. Accident Analysis \& Prevention, 26(5), 555-562.

Reisinger, H. (1997). The impact of research deigns on $\mathrm{R}^{2}$ in linear regression models: An exploratory meta-analysis. Journal of Empirical Generalizations in Marketing Science, 2, 1-12.

Ritchey, M. \& Nicholson-Crotty, S. (2011). Deterrence theory and the implementation of speed limits in the American states. The Policy Studies Journal, 39(2), 329-346.

Stephens, A. N., Nieuwesteeg, M., Page-Smith, J., \& Fitzharris, M. (2017). Self-reported speed compliance and attitudes towards speeding in a representative sample of drivers in Australia. Accident Analysis and Prevention, 103, 56-64. https://doi.org/10.1016/j.aap.2017.03.020

Sullman, M. J. M., \& Taylor, J. E. (2010). Social desirability and self-reported driving behaviours: Should we be worried? Transportation Research Part F, 13, 215-221.

Thomas, L. J., Srinivasan, R., Decina, L. E., \& Staplin, L. (2008). Safety effects of automated speed enforcement programs: Critical review of international literature. Transportation Research Record, 2078(1), 117-126.

https://doi.org/10.3141/2078-16

Tselentis, D. I., Vlahogianni, E. I., \& Yannis, G. (2019). Driving safety efficiency benchmarking using a smartphone data. Transportation Research Part C, 109, 343-357.

Turner, B. (2013). Implementing the safe system approach to road safety: Some examples of infrastructure related approaches. In: Proceedings of the 16th International Conference Road Safety on Four Continents: Beijing, China. 15-17 May 2013.

Vlahogianni, E. I., \& Barmpounakis, E. N. (2017). Driving analytics using smartphones: Algorithm, comparisons and challenges.
Transportation Research Part C, 79, 196-206. https://doi. org/10.1016/i.trc.2017.03.014

Vlassenroot, S., Broekx, S., De Mol, J., Panis, L. I., Brijs, T., \& Wets, G. (2007). Driving with intelligent speed adaptation: Final results of the Belgian ISA-trial. Transportation Research Part A, 41, 267-279. https://doi.org/10.1016/j.tra.2006.05.009

West, R., French, D., Kemp, R., \& Elander, J. (1993). Direct Observation of Driving, Self Reports of Driver Behavior, and Accident Involvement. Ergonomics, 36(5), 557-567.

Yamamura, E. (2008). Impact of formal and informal deterrents on driving behavior. The Journal of Socio-Economics, 37, 2505-2512. https://doi.org/10.1016/j.socec.2007.12.004 